\title{
Advancing the use of scenarios to understand society`s capacity to achieve the 1.5 degree target
}

\begin{abstract}
With a range of potential pathways to a sustainable future compatible with the Paris Agreement $1.5^{\circ} \mathrm{C}$ target, scenario analysis has emerged as a key tool in studies of climate change mitigation and adaptation. A wide range of alternative scenarios have been created, and core amongst these are five socio-economic scenarios (Shared Socio-economic Pathways or SSPs) and four emission scenarios (Representative Concentration Pathways or RCPs). Whilst mitigation scenarios (the Shared Policy Assumptions, or SPAs) have been developed for each SSPRCP combination, describing the actions necessary to match the climate pathway of the RCP, there has not yet been a systematic approach to address whether and how these actions can be enabled in practice.
\end{abstract}

We present a novel and transferable framework to understand society's capacity to achieve the $1.5^{\circ} \mathrm{C}$ target, based on four participatory case studies using the SSP-RCP scenarios. The methodology builds on a framework for categorising different types of societal capitals and capacities and assessing their impact on the potential to implement different types of mitigation actions. All four case studies show that SSP1 has the highest potential to reach the target. Although environmental awareness is high in both SSP1 and SSP4, continued social inequalities in SSP4 restrict society's capacity to transform, despite economic growth. In the two least environmentally-aware SSPs, SSP3 and SSP5, the transformation potential is low, but the view on capitals and capacities nonetheless helps identify opportunities for actors to develop and implement mitigation actions.

The study highlights that techno-economic assessments of climate strategies need to be complemented by consideration of the critical role played by social and human capital, and by societal capacity to mobilise and create these capitals despite different socio-economic trends. These capitals and capacities are essential to enable the rapid innovation, behavioural change and international co-ordination needed to achieve the $1.5^{\circ} \mathrm{C}$ target.

Keywords: SSP-RCP scenarios; capitals; capacities; mitigation; transformation; 1.5 degree target

\section{Introduction}

The ambition of the Paris climate agreement to limit global temperature increase to $1.5^{\circ} \mathrm{C}$ by 2100 creates a pressing demand to find ways to achieve this goal (Hulme, 2016; Rogelj et al., 2016). The IPCC special report on the $1.5^{\circ} \mathrm{C}$ target presents four illustrative pathways, which all involve major transformation of the energy system together with large-scale changes to human behaviour and land-use (IPCC, 2018). These changes pose major political challenges, and some authors argue that the $1.5^{\circ} \mathrm{C}$ target will be unattainable without resorting to highrisk, large-scale geo-engineering (Akimoto et al., 2017). Others, however, claim that limiting global temperature increases to $1.5^{\circ} \mathrm{C}$ is possible through action-led, societal transformation (Hermwille, 2016; O'Brien, 2015; Rockström et al., 2017; Tàbara et al., 2013; Tàbara et al., 2018a, Westley et al., 2011). 
With such different potential pathways to a sustainable future, scenario analysis has emerged as a key tool in studies of climate change mitigation and adaptation, and a wide range of alternative socio-economic and climate scenarios have been created (Akimoto et al., 2017; Friedlingstein et al., 2014; Rogelj et al., 2016; Rogelj et al., 2009; Rogelj et al., 2015). Core amongst these are the five socio-economic scenarios (Shared Socio-economic Pathways or SSPs) and four emission scenarios (Representative Concentration Pathways or RCPs), which have been developed in parallel (Moss et al., 2010) and are intended to be independent yet complementary (O'Neill et al., 2016; van Vuuren et al., 2014). The RCPs describe the evolution of future greenhouse gas concentrations and associated climate impacts without any assumptions on mitigation actions. The SSPs explore different socioeconomic futures and the challenges they present for climate mitigation and adaptation (O'Neill et al., 2015) as socio-economic factors enable or constrain the actions needed to meet climate and sustainability targets (O'Neill et al., 2016). For example, scenarios including high investment in green technology and low energy demand reduce the additional effort required for climate mitigation, whereas scenarios assuming high levels of human well-being and flexible institutions may enable easier adaptation to climate change (O’Neill et al., 2017). For each SSP, a baseline scenario describes a future socio-economic trajectory assuming no climate change and no additional climate policy actions (Riahi et al., 2017). For each SSP-RCP combination, a set of internally-consistent Shared Policy Assumptions (SPAs) has been developed that describes the additional mitigation actions that would need to be taken (beyond the SSP baseline) to match the climate pathway of the RCP (Riahi et al., 2017).

Whilst the SSP-RCP scenario matrix has been designed to be relevant to end-users (such as decision-makers, policymakers and practitioners) and consistent with climate policy assumptions (Carlsen et al., 2013; Kriegler et al., 2014; Kriegler et al., 2012), there are limits to its utility in decision-making contexts for several reasons. Firstly, the new scenarios were not designed as a direct tool for policy-makers, but rather for researchers to produce climate assessments that will then be shared with policy-makers (Moss et al. 2010). As a result, policy-makers report "poor understandability of scenario data" (Pilli-Sihvola et al., 2015). Secondly, the global SSPs may not be suitable for use in all applications (e.g. a different spatial scale or context)" (Nilsson et al., 2017). Thirdly, such externallycreated scenarios may not be well connected to the users' worldviews, impacting their understanding of and buyin to the scenarios (Lempert, 2013). There is therefore a need to better connect the knowledge of climate researchers and policy-makers (Klein and Juhola, 2014; Pilli-Sihvola et al., 2015) in order for the new scenarios to inform better adaptation and mitigation planning.

In this study, we advance the use of combined SSP-RCP scenarios to explore systematically future society's ability to achieve the $1.5^{\circ} \mathrm{C}$ target, by identifying the potential to transform as a function of capitals and capacities in the SSP-RCP combinations. Our methodology identifies the elements that 'enable' climate action in each SSP through an assessment of i) five capital stocks available for society to draw upon (human, social, natural, financial and manufactured capital), and ii) four types of agency capacities (stewarding, unlocking, transforming and orchestrating) through which actors are able to leverage these capitals and enact change. To this end, we developed and applied a novel, cross-scale and transferable approach combining capitals (as indicators of the material and non-material resources available) with actors' collective capacities for change, consistent with each combined SSP-RCP scenario for a series of nested case studies from global to European sub-national scales. We discuss how 
this framework of capitals and capacities provides relevant information to decision-makers on the possible future challenges and opportunities associated with the $1.5^{\circ} \mathrm{C}$ target.

\section{Methodology}

This study builds on the SSP-RCP framework to identify how different scenarios enable or constrain the achievement of the $1.5^{\circ} \mathrm{C}$ target, for each of four case studies. We start with the recognition that the $1.5^{\circ} \mathrm{C}$ target requires strong action, involving not just technological and social development but also institutional change, behavioural change and land-use change, consistent with the level of mitigation action reported in integrated assessments globally (Riahi et al., 2017) and regionally (van der Zwaan et al., 2016). The IPCC Special Report on $1.5^{\circ} \mathrm{C}$ highlights the importance of this framework, by stating that "strengthened multi-level governance, institutional capacity, policy instruments, technological innovation and transfer and mobilization of finance, and changes in human behaviour and lifestyles are enabling conditions that enhance the feasibility of achieving the $1.5^{\circ} \mathrm{C}$ target" (IPCC, 2018). This recognition requires moving beyond the original distinction between "challenges to adaptation and challenges to mitigation" that defines the uncertainty space of the SSPs, and adopting a more holistic approach geared towards understanding what the SSPs mean for achieving fundamental societal transformation (Westley et al., 2011; Feola, 2015; Hermwille, 2016; Gillard et al., 2016; IPCC 2018).

Societal transformations are ultimately driven by different actors - both individuals or organisations representing different societal spheres (governments, communities, market and third sector) - who consciously or unconsciously act to change the state of human and natural systems (O'Brien, 2015; 2016; Avelino and Wittmayer, 2016). As these actors are embedded within societal structures (e.g. formal and informal institutions, social networks, resource distribution), their capacities are manifest in the extent to which they are able to mobilise, create and change these structures (Giddens, 1979) - in terms of institutions, resources, networks etc. We therefore base our methodology on assessing two key sets of indicators:

1. Stocks of five types of capital: human, social, natural, manufactured and financial, with a focus on human and social capital because they underpin the potential for transformational societal change;

2. Four types of capacity that give actors the agency to mobilise, create and change the stocks of these five capitals: stewarding, unlocking, transforming, orchestrating.

The main goal of our methodology is to identify which stocks of capital can be mobilised by which types of actors in each scenario combination. Whether and how actors are able to mobilise capitals is analysed by drawing on a systematic framework of their capacities for transformation (Hölscher et al., 2018a). The actors are identified inductively in the scenario narratives, and are integrated into the capacity analysis.

The first step of our methodology was to link the capitals and capacities to potential mitigation actions in a theoretical framework (Section 2.1). We then applied this framework within four case-studies (Section 2.2). In the results (Section 3) we interpret the joint impact of the capacities and capitals on the potential for society to meet 
the $1.5^{\circ} \mathrm{C}$ target under each scenario, and show how these findings relate to Integrated Assessment Modelling approaches.

\subsection{Capital stocks and societal capacities that constrain and enable actions towards the $1.5^{\circ} \mathrm{C}$ target}

"Capitals" are defined as stocks yielding a benefit valued by humans (Porritt, 2007). The concept of capitals is useful for providing information on the enabling conditions in scenarios. They are straightforward (Tinch et al., 2015) and provide a more systemic understanding than economic- or population-based indicators. In this study, we consider five capitals: human (education, knowledge, health), social (individual relationships, societal trust, institutions and networks), manufactured (technology and infrastructure), natural (ecosystems) and financial (markets) (Jäger et al., 2015; Porritt, 2007; Tinch et al., 2015).

Whether and how the capital stocks can be mobilised, created and changed to achieve the $1.5^{\circ} \mathrm{C}$ target essentially depends on questions of agency (Westley et al. 2011, Gillard et al., 2016). In other words, who in the scenario narrative has abilities to mobilise, create and change societal structures (e.g. formal and informal institutions, social networks), knowledge, beliefs and resources for developing and implementing strategies and actions (Garud et al. 2007; Boyd et al. 2014; Westley et al., 2013). We employ the concept of capacities for understanding the abilities of actors in the scenarios to effectively mobilise, create and change capital stocks. At the same time, capital stocks can constrain or enable actors in using their capacities.

Different types of capacities can be identified that fulfil distinct functions for developing and implementing transformative strategies and responding to different types of transformation dynamics: stewarding, unlocking, transforming and orchestrating (Table 1) (Hölscher et al. 2018a; Hölscher et al. 2018b). These capacities build on a literature review of sustainability transitions and resilience approaches that are concerned with transformative change and agency (Grin et al., 2010; Loorbach et al., 2017; Folke 2016; Olsson et al., 2014; Westley et al., 2013). The three levels of capacity defined in Table 1 are based on the authors' interpretation and synthesis of the literature review and are subsequently used during the scenario analysis (see Section 2.2).

Table 1: Interpretation of capacities to measure enabling and disabling conditions in combined SSP-RCP scenarios. The literature reviewed to assess the level of capacity is indicated in column 1 , below the definition of each capacity

\begin{tabular}{|c|c|c|c|}
\hline Capacities & Low & Medium & High \\
\hline $\begin{array}{l}\text { Stewarding (Ability } \\
\text { to anticipate, protect } \\
\text { and recover from } \\
\text { disturbances } \\
\text { exploiting } \\
\text { opportunities } \\
\text { beneficial } \\
\text { sustainability) } \\
\text { (Chapin et al., } 2010 \text {; }\end{array}$ & $\begin{array}{l}\text {-Low social cohesion. } \\
\text {-Risk-numb: No desire for } \\
\text { long-term planning and } \\
\text { reactive risk management. } \\
\text {-Coping, no reflexivity. }\end{array}$ & $\begin{array}{l}\text {-Communities of interest } \\
\text { without collective identity. } \\
\text {-Risk-averse: Mid-term } \\
\text { planning to control risk. } \\
\text {-Fragmented know-how } \\
\text { (without } \quad \text { knowledge } \\
\text { integration). }\end{array}$ & $\begin{array}{l}\text {-Strong social networks and } \\
\text { supportive social contexts. } \\
\text {-Proactive long-term } \\
\text { integrated planning. Risk } \\
\text { taking and uncertainty } \\
\text { embracing. } \\
\text {-Collective memory and } \\
\text { learning (reflexivity, } \\
\text { integration of knowledge). }\end{array}$ \\
\hline
\end{tabular}




\begin{tabular}{|c|c|c|c|}
\hline $\begin{array}{l}\text { Folke et al., 2005; } \\
\text { Garmestani } \\
\text { Benson, 2013) }\end{array}$ & & & \\
\hline $\begin{array}{l}\text { Unlocking (Ability to } \\
\text { recognise and } \\
\text { dismantle drivers of } \\
\text { unsustainability and } \\
\text { path-dependencies) } \\
\text { (Geels, 2014; } \\
\text { Kivimaa and Kern, } \\
2016 \text { ) }\end{array}$ & $\begin{array}{l}\text {-Acceptance and support of } \\
\text { existing institutions, values } \\
\text { and practices. } \\
\text {-Powerful interest networks } \\
\text { to maintain status quo. }\end{array}$ & $\begin{array}{l}\text {-Uncoordinated counter- } \\
\text { movements. } \\
\text {-Competing interest networks } \\
\text { along with weaker counter- } \\
\text { networks. }\end{array}$ & $\begin{array}{l}\text {-No support for status-quo. } \\
\text {-Effective opposition } \\
\text { networks. }\end{array}$ \\
\hline $\begin{array}{l}\text { Transforming } \\
\text { (Ability to create } \\
\text { novelties and embed } \\
\text { them in practices) } \\
\text { (Frantzeskaki et al., } \\
\text { 2012; Raven et al. } \\
\text { 2010; Westley et al., } \\
\text { 2013) }\end{array}$ & $\begin{array}{l}\text {-Low investments in and no } \\
\text { leadership for innovation. }\end{array}$ & $\begin{array}{l}\text {-Innovation and competition } \\
\text { for specific interests. }\end{array}$ & $\begin{array}{l}\text {-Leadership for innovation. } \\
\text {-Learning from tested } \\
\text { solutions (e.g upscaling and } \\
\text { replicating). }\end{array}$ \\
\hline $\begin{array}{l}\text { Orchestrating } \\
\text { (Ability to coordinate } \\
\text { multi-actor processes } \\
\text { to maximise } \\
\text { synergies) (Chan et } \\
\text { al., } 2015 \text {; } \\
\text { Frantzeskaki et al., } \\
\text { 2014; Hodson and } \\
\text { Marvin, 2010) }\end{array}$ & $\begin{array}{l}\text {-No shared development } \\
\text { goals and frameworks. } \\
\text {-Low collaboration across } \\
\text { scales and sectors. } \\
\text {-No transparency in } \\
\text { decision-making. }\end{array}$ & $\begin{array}{l}\text {-Shared and long-term } \\
\text { development goals between } \\
\text { small groups. } \\
\text {-Collaboration limited by } \\
\text { competition across scales and } \\
\text { sectors. } \\
\text {-Good governance but no } \\
\text { political culture. }\end{array}$ & $\begin{array}{l}\text {-Shared and long-term } \\
\text { development goals } \\
\text {-Collaboration across scales } \\
\text { and sectors. } \\
\text {-Good governance, with } \\
\text { engaged political culture. }\end{array}$ \\
\hline
\end{tabular}

The theoretical framework facilitates the integration of human and societal dimensions of agency (via the capacities) into the analysis of adaptation, mitigation and transformation. To do this, we divide actions into four broad categories: technological, institutional, lifestyle and land-based, based on expert judgement of our interdisciplinary authorship team. In our framework, these categories each depend on a different mix of capital stocks, and require the relevant actors and capacities to mobilise these stocks (Figure 1). Using mitigation action as an example, technological mitigation involves developing and investing in new and improved technologies such as energy supply and energy efficiency, carbon capture and storage and (in some scenarios) 'geo-engineering', requiring high stocks of financial and manufactured capital as well as social and human capital for technical expertise. This therefore links with the transformative capacity for innovation and learning (capacity "T" in Figure 1). Institutional action includes governance-related actions such as taxation, regulation and market reform (e.g. carbon trading). Lifestyle change includes individual and collective actions that reduce demand for energy and resources, including dietary change and waste avoidance. Both institutional and lifestyle change require high levels of social and human capital. To mobilise these capitals towards institutional change, all four capacities are required. For individual lifestyle change, the focus is on the capacity to build flexible networks of individuals (stewarding), social innovation (transforming) and effective counter-movements (unlocking). Land-based mitigation (including 
reduced emissions from agriculture, increased carbon storage and sequestration in soils and vegetation, and bioenergy with or without carbon capture and storage) requires integrated, co-ordinated and long term planning as well as know-how (stewarding, transformative and orchestrating capacities).

The crucial point in the framework is that the level of societal transformation required to meet the $1.5^{\circ} \mathrm{C}$ target cannot be achieved through only one type of action, e.g. technological action alone, due to spillovers and tradeoffs (IPCC, 2018). According to this reasoning, mobilising capital stocks to enable the full spectrum of actions requires all four types of capacity. However, the societal context (in this study, the combined SSP-RCP scenarios) determines which capacities and which types of action will be feasible.

Action Types
Technological
Institutional
Life-style
Land-based

Capitals
\begin{tabular}{|c|c|c|c|c|}
\hline S & H & N & F & M \\
\hline S & H & N & F & M \\
\hline S & H & N & F & M \\
\hline S & H & N & F & M \\
\hline
\end{tabular}

Actors
\begin{tabular}{|c|c|c|c|}
\hline $\mathbf{G}$ & $\mathbf{C}$ & $\mathbf{M}$ & $\mathbf{T}$ \\
\hline $\mathbf{G}$ & $\mathrm{C}$ & $\mathrm{M}$ & $\mathrm{T}$ \\
\hline G & $\mathbf{C}$ & M & T \\
\hline $\mathbf{G}$ & $\mathbf{C}$ & $\mathbf{M}$ & $\mathbf{T}$ \\
\hline
\end{tabular}

Capacities
\begin{tabular}{|c|c|c|c|}
\hline S & U & T & O \\
\hline S & U & T & O \\
\hline S & U & T & O \\
\hline S & U & T & O \\
\hline
\end{tabular}

Figure 1: Elements of the theoretical framework to analyse the potential to reach the $1.5^{\circ} \mathrm{C}$ target. Capitals are social (S), human (H), natural (N), financial (F), manufactured (M). Actors are governments (G), communities (C), markets (M), third sectors such as NGOs and research $(T)$. Capacities are: stewarding $(S)$, unlocking $(U)$, transformative $(T)$, orchestrating $(O)$. The darker shaded cells with bold lettering are capitals, actors and capacities which are most influential in determining the effectiveness of a given mitigation type

\subsection{Case studies: participatory development of SSPs for the European region, Iberia, Hungary and Scotland}

This theoretical framework has been applied in four case studies: Europe as a whole (the 2013 EU 27 plus Switzerland and Norway); Scotland, the Iberian Peninsula (Spain and Portugal) and two municipalities in Hungary. SSPs were co-produced with stakeholders for each case study: the 'Eur-SSPs' for Europe and the three 'local SSPs': Scottish, Iberian and Hungarian.

The European and Scottish case studies focus on the cross-sectoral impacts of land-use and climate change, linking urbanisation, agriculture, water resources, forestry and biodiversity sectors (Kok et al. 2017a; Harrison et al. 2018). Both European and Scottish case studies build from previous scenario work in the CLIMSAVE project (Harrison et al. 2015; Holman et al. 2016) and have been further developed to include the socio-economic and climate drivers of the SSPs and RCPs (Kok et al. 2017a). The Iberian and Hungarian case studies focus on the sectors and impacts that are more relevant to local societal interests. For Iberia the focus is on impacts on agro-forest systems and governance of transboundary river basins (Tàbara et al. 2018b) while for Hungary the focus is on impacts of population dynamics on urban land-use and health (Li et al. 2018). 
The scenarios have been developed by engaging stakeholders to develop the scenario narratives and review the analyses (Tàbara et al. 2018b), therefore ensuring that scenarios are diverse enough to be relevant for and driven by stakeholders but still comparable in terms of structure and process.

In line with van Ruijven et al. (2014), the local SSPs are consistent with the global SSPs, while allowing for specific characteristics, depending on the stakeholders' choice of key drivers of change and their interpretation of the global and Eur-SSPs. The local and Eur-SSPs describe a range of challenges to adaptation and mitigation, which have been interpreted as varying levels of inequality and carbon intensity (Figure 2). Eur-SSP1 and EurSSP5 develop into relatively inclusive societies, whereas Eur-SSP3 and Eur-SSP4 are highly unequal. Eur-SSP1 and Eur-SSP4 are less carbon-intensive than Eur-SSP3 and Eur-SSP5. A European SSP2 was not developed as it was interpreted to converge to the average of the other scenarios, and therefore was less suitable than the other SSPs for identifying alternative capacities and challenges. We refer to Kok and Pedde (2016) for the Eur-SSPs and local SSPs and to the Supplementary Material for the sketch of all the SSP narratives for all case studies.

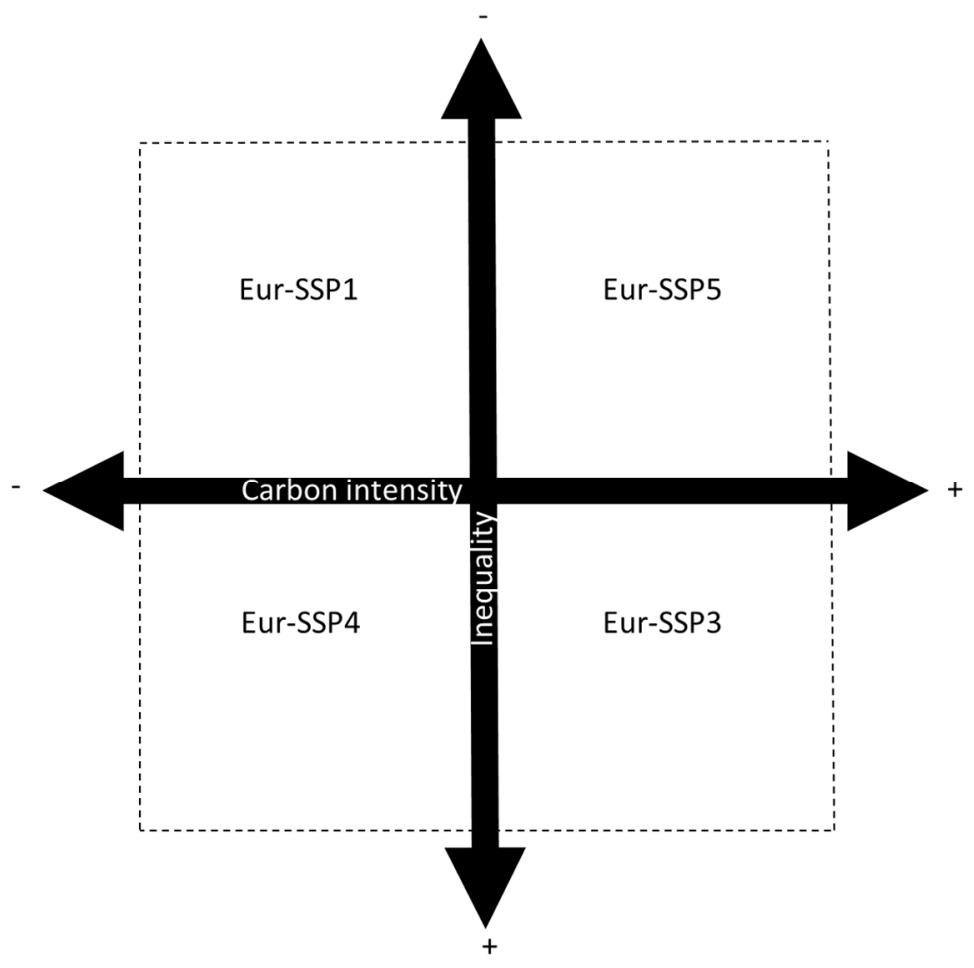

Figure 2: Interpretation of challenges to adaptation (inequality) and mitigation (carbon intensity) of the European SSPs

The Eur-SSPs and local European SSPs combined with the respective RCP can be used to structure "what could happen" and map the trend onto a theoretical space in time (until 2100) and to show the distance from "what do we want", i.e. the $1.5^{\circ} \mathrm{C}$ target (Figure 3). The combining of each SSP with an RCP was based on the challenges to mitigation. SSP1 and SSP4 have lower challenges to mitigation so they were combined with RCP4.5, while SSP3 and SSP5 were combined with RCP8.5. 


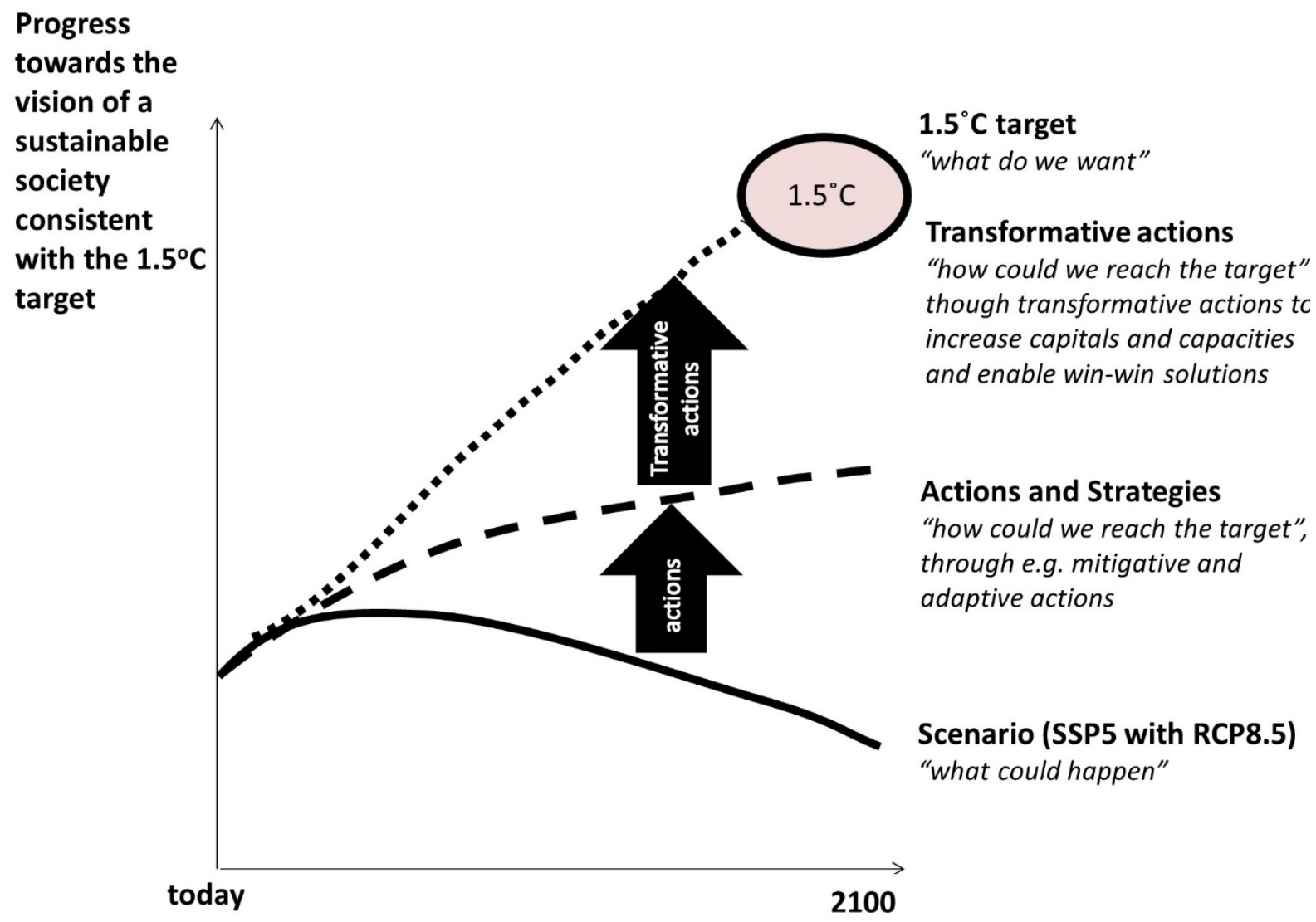

Figure 3: Conceptualisation of scenarios as context to develop mitigation and adaptation pathways to reach a desired vision in 2100. The actions to develop sustainable pathways towards the vision build from the scenario and are scenario-contextualised in time.

This conceptualisation is consistent with the original separation between SSPs and SPAs. Actions (SPAs) are not included in our combined SSP-RCP scenarios but are enabled or constrained by the differing capacities of the actors and capitals in each SSP-RCP combination. In this reasoning, SSP-RCP represents the societal potential to transform, and the SPAs represent societal action towards transformation. The SSP-RCP context thus needs to contain information on what conditions exist to enable (or constrain) the additional actions needed to reach the $1.5^{\circ} \mathrm{C}$ target.

The participatory process to develop the Eur-SSPs and local SSPs consisted of workshops in which stakeholders addressed the exploratory question: “what could happen?" (Börjeson et al. 2006). The workshops were professionally facilitated (Gramberger et al. 2015) and used an analytical method for analysing qualitative and semi-quantitative variables in order to bridge qualitative and quantitative scenarios (Pedde et al. 2018). As part of this, the level (low-medium-high) of each type of capital was defined for each scenario in each of three time-slices (2010-2040, 2041-2070 and 2071-2100). The trends in capitals are reported in Supplementary Material and categorised in Figure 4. 
Subsequently, the scenario narratives were interpreted to qualitatively assess the capacities against the categories and levels of capacities of Table 1. The capacities interpreted for each scenario narrative were then combined with the stakeholder-derived capital trends to assess the potential of society to transform to achieve the $1.5^{\circ} \mathrm{C}$ target. The potential was then interpreted against the categories of mitigation actions to define what mitigation is feasible and this was compared with potential identified with the global SSP-RCP mitigation pathways (Riahi et al., 2017).

\section{Results: Capacities and capitals in SSPs}

\subsection{Availability of capitals and capacities across SSPs}

The results show the levels of capacities and capitals available in the SSPs to transform society to function consistently with the requirements to achieve the $1.5^{\circ} \mathrm{C}$ target. The availability of capitals and capacities in each case study is summarised in Figure 4. 


\begin{tabular}{|c|c|c|c|c|c|c|c|c|c|c|c|}
\hline \multirow{6}{*}{$\overline{\tilde{n}}$} & \multirow{2}{*}{ Region } & \multicolumn{5}{|c|}{ Capitals } & \multirow{2}{*}{ Storyline } & \multicolumn{4}{|c|}{ Capacities } \\
\hline & & $\mathrm{H}$ & $\mathrm{S}$ & M & $\mathrm{F}$ & $\mathrm{N}$ & & $\mathrm{S}$ & $\mathrm{T}$ & $\mathrm{O}$ & $\mathrm{U}$ \\
\hline & Europe & & & & & & $\begin{array}{l}\text { High commitment to achieve sustainable development goals through effective governments and } \\
\text { global cooperation, ultimately resulting in less inequality and less resource intensive lifestyles }\end{array}$ & & & & \\
\hline & Scotland & & & & & & $\begin{array}{l}\text { Effective regulation ("communitarianism"), stable but slower economic growth and social } \\
\text { participation lead to a sustainable Scotland }\end{array}$ & & & & \\
\hline & Iberia & & & & & & $\begin{array}{l}\text { Triggered by continuing and growing social participation in environmental, social, and economic } \\
\text { issues and fuelled by a European social-oriented political framework, Iberia embraces a path } \\
\text { towards a new development model }\end{array}$ & & & & \\
\hline & Hungary & & & & & & $\begin{array}{l}\text { A transparent and multi-level governance leads to a prosperous and greener Hungary } \\
\text { characterised by local circular economies and integration in Europe }\end{array}$ & & & & \\
\hline \multirow{5}{*}{$\hat{\tilde{n}}$} & Region & $\mathrm{H}$ & $\mathrm{S}$ & M & $\mathrm{F}$ & $\mathrm{N}$ & Storyline & S & $\mathrm{T}$ & O & $\mathrm{U}$ \\
\hline & Europe & & & & & & $\begin{array}{l}\text { Sparked by economic woes in major economies and regional conflict, antagonism between and } \\
\text { within regional blocs increases, resulting in the disintegration of social fabric and many } \\
\text { countries struggling to maintain living standards }\end{array}$ & & & & \\
\hline & Scotland & & & & & & $\begin{array}{l}\text { Driven by resource pressure and migration, rivalry between social groups explodes, resulting in } \\
\text { feudal-like systems where the have-nots work to provide the haves. Everyone learns to live with } \\
\text { less }\end{array}$ & & & & \\
\hline & Iberia & & & & & & Short-lived governments lead to a fragmentation of the social and economic fabric in Iberia & & & & \\
\hline & Hungary & & & & & & $\begin{array}{l}\text { Hungary finds itself in a 'war zone' between competing regional powers. A day-to-day mentality } \\
\text { establishes. This leads to social fragmentation, stratification and sectarianism. }\end{array}$ & & & & \\
\hline \multirow{5}{*}{$\stackrel{+}{\tilde{n}}$} & Region & $\mathrm{H}$ & $\mathrm{S}$ & M & $\mathrm{F}$ & $\mathrm{N}$ & Storyline & $\mathrm{S}$ & $\mathrm{T}$ & $\mathrm{O}$ & $\mathrm{U}$ \\
\hline & Europe & & & & & & $\begin{array}{l}\text { Globally, power and economic opportunities concentrate in a relatively small political and } \\
\text { business elite, leading to substantial proportions of populations having a low level of } \\
\text { development. Europe, as a whole, becomes an important player in a world full of tensions }\end{array}$ & & & & \\
\hline & Scotland & & & & & & $\begin{array}{l}\text { The private sector gains political power and the country is ruled by few multinationals. Wealthy } \\
\text { live in eco-communities, while social unrest slowly takes over, resulting in the revolutionary } \\
\text { "tartan spring" }\end{array}$ & & & & \\
\hline & Iberia & & & & & & $\begin{array}{l}\text { Higher inequalities lead to substantial proportions of the population having a low level of } \\
\text { development and a "subtle" enforcement of inequality, while an increase in renewable energies } \\
\text { business is very lucrative for the political elite }\end{array}$ & & & & \\
\hline & Hungary & & & & & & $\begin{array}{l}\text { With social inequalities and power centralisation on the rise, Hungary becomes a socio- } \\
\text { economically stratified country. Resources are scarce for the have nots. Local communities self- } \\
\text { organise at the periphery of an elitist regime }\end{array}$ & & & & \\
\hline \multirow{5}{*}{$\ddot{\tilde{n}}$} & Region & $\mathrm{H}$ & S & M & $\mathrm{F}$ & $\mathrm{N}$ & Storyline & $\mathrm{S}$ & $\mathrm{T}$ & $\mathrm{O}$ & $\mathrm{U}$ \\
\hline & Europe & & & & & & $\begin{array}{l}\text { Competitive markets, innovation and participatory societies produce rapid technological } \\
\text { progress and development of human capital as the path to sustainable development. A lack of } \\
\text { environmental concern leads to the exploitation of abundant fossil fuel resources }\end{array}$ & & & & \\
\hline & Scotland & & & & & & $\begin{array}{l}\text { Establishment of for-profit publically owned energy companies, such as Statoil and the Scotland } \\
\text { Energy Corporation (SEC), leads to high revenues, redistributed with egalitarian social policies. } \\
\text { High employment and population growth, but higher pressure on the environment }\end{array}$ & & & & \\
\hline & Iberia & & & & & & $\begin{array}{l}\text { Iberia becomes dependent on technology, fossil fuels, subsidies from the EU and gas from } \\
\text { northern Africa, and investments of large corporations. Eventually this development model } \\
\text { collapses }\end{array}$ & & & & \\
\hline & Hungary & & & & & & $\begin{array}{l}\text { Economic growth and rigid governance schemes hook Hungary to fossil fuel development } \\
\text { model. Eventually, this leads to environmental degradation and atomizing society: Hungary ends } \\
\text { in turmoil }\end{array}$ & & & & \\
\hline
\end{tabular}

Figure 4: Overview of the SSP analysis for four case studies ("regions") with levels of capitals and capacities indicated by the colour: green=high; orange=medium; red=low; white=not quantified. Capitals are social (S), human (H), natural (N), financial (F), manufactured (M). Capacities are: stewarding (S), unlocking (U), transformative (T), orchestrating (O). 
In all case studies, SSP1 achieves the highest capitals and capacities because of the active participation of all types of actors (market, research, government and third sector) towards sustainability. In the Eur-SSP1, strong international cooperation and institutions, most importantly the political integration of European countries in view of shared sustainability priorities, enable the establishment of multi-level governance and an early shift towards a sustainability focus. European institutions also play a positive role in enabling a strong early push towards sustainability in the Hungarian and Iberian SSP1 (a "European social framework" in Iberia and the European Union in Hungary), in combination with bottom-up participation and municipality-level sustainability-oriented investments and governance. Only in the Scottish SSP1 the trigger towards sustainability is not directly enabled by the European Union but rather by the Scottish government.

The rapid transition towards sustainability in SSP1 leads to the maintenance and further steady creation of capacities until 2100. Societal and environmental awareness is generated early in the scenario, resulting in high levels of human and social capital and thus in high orchestrating, transformative and stewarding capacity. The unlocking capacity that has supported the establishment of effective counter-movements and social innovation decreases towards 2100 , as the new sustainability paradigm is established and the importance of opposition networks decreases.

In SSP3, capacities and capitals decline in all case studies. The cause of the overall decrease of capacities is the focus on short-term governance, weak leadership and low investment for innovation. The lack of reflexivity and learning from tested solutions results in generally low stewarding, transformative and orchestrating capacities, apart from in the Scottish case study, where governance and innovation are managed by large companies. However, unlocking capacity brings the potential for novel networks, unconstrained by top-down enforcement given the lack of leadership. The potential for a reversal of the status-quo is limited by the general lack of coordination and competing interests of counter-movements.

In SSP4, capacities tend to average at medium level for two main reasons: societal fragmentation and a combination of low capacity for local actors with higher capacity of actors at national or European level. In Europe, Iberia and Scotland, powerful multinationals exert a stabilising influence which enables cooperation (orchestrating capacity) and innovation (transformative capacity). These capacities are however exercised in a very top-down manner due to the concentration of power, and learning is limited due to competition, political and economic power-grabbing and large-scale social exclusion. In Hungary, social networks and reflexive learning together with the existence of counter-movements until 2070 generate high stewarding and unlocking capacity, enabling communities to push for sustainability and resilience. At national level, however, the focus is on day to day survival and coping, low investments, and rigid top-down maintenance of status throughout the whole scenario, de facto decreasing the potential of local actors.

SSP5 shows the greatest variation of capitals and capacities between case studies. Natural capital is low in all SSP5 case studies, while human and social capitals are high in Europe and Iberia but low in Scotland and Hungary. Although all SSP5 case studies share the common traits of economic development and social equality, the effect of individualism, economic growth (linked to high resource exploitation and consumption) and environmental 
damage were perceived differently in different case studies. Scotland and Iberia end up with medium unlocking capacity, consistent with lack of support for the status-quo and effective opposition. Because other capacities and/or capitals are limited, overall potential remains close to "medium", except for Europe (and Scotland, to an extent) where potential is "high" due to the availability of knowledge, capitals, technology and preparedness to shift to "re-emergence of investments in renewables" when needed.

\subsection{Potential to transform}

In Figure 5, we show the overall potential of Eur-SSPs to transform societies towards a $1.5^{\circ} \mathrm{C}$-consistent world as a function of capitals and capacities. Letters representing each of the four capacities $(\mathrm{S}, \mathrm{U}, \mathrm{T}, \mathrm{O})$ are plotted on a scale of high-medium-low (according to the definitions in Table 1) on the x-axis, and their position on the y-axis is determined by the combined level of human and social capital (the capitals that underpin social transformation). The colour of the boxes indicates how these levels of capitals and capacities combine to determine society's overall potential to achieve the $1.5^{\circ} \mathrm{C}$ target in each scenario, from "very low" to "very high". For example, in the EurSSP1 the potential for achieving the $1.5^{\circ} \mathrm{C}$ target is "very high" as a result of "high" social and human capitals, "high" stewarding, orchestrating and transformative capacity and "medium" unlocking capacity; whereas EurSSP3 results in "low" potential because of overall "low" capitals, "low" stewarding and orchestrating capacity, "medium" transformative capacity, and "high" unlocking capacity.
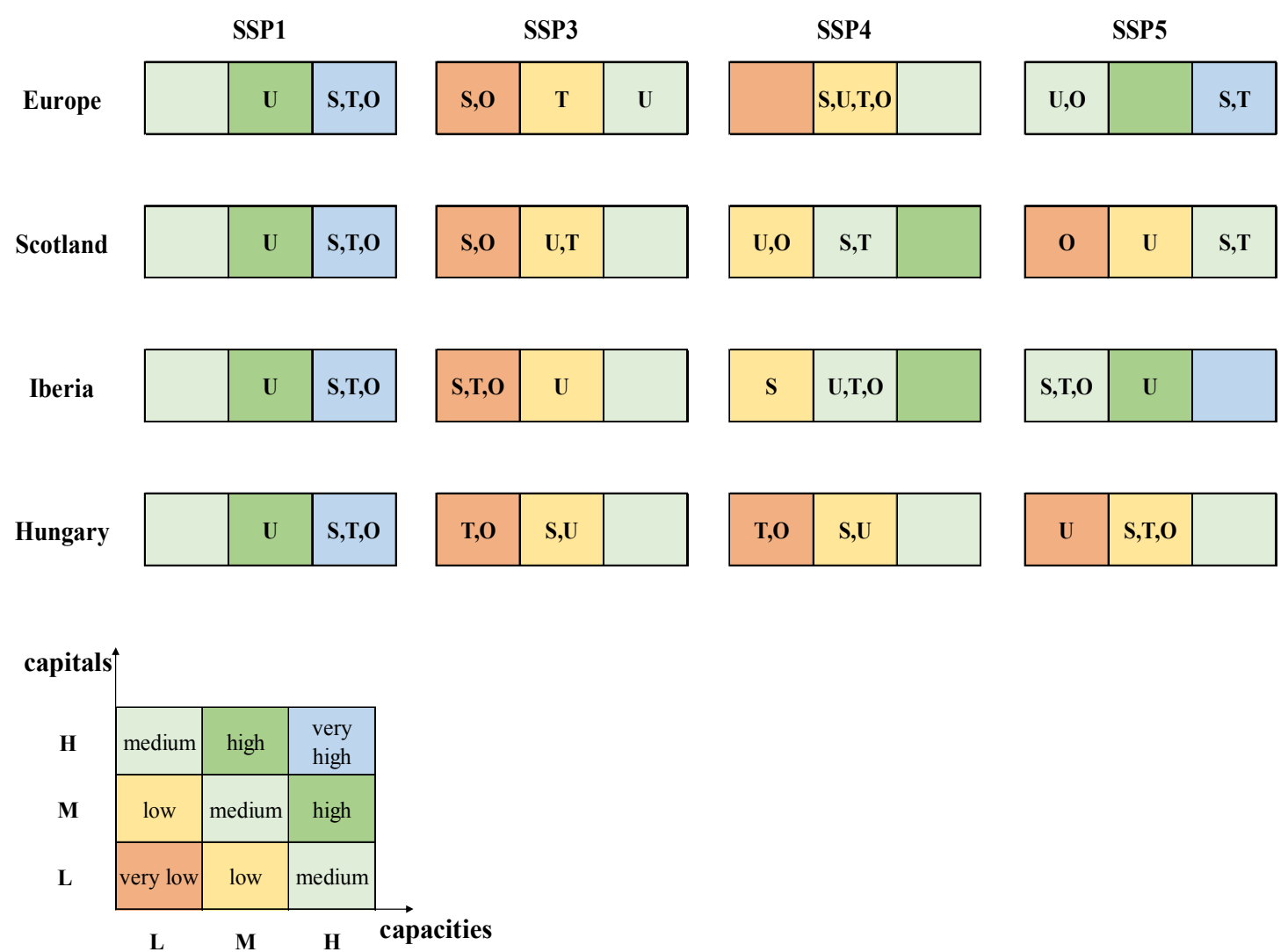

Legend: the potential of societies to transform consistently with a $1.5^{\circ} \mathrm{C}$ world

Figure 5: Analysis of the potential to transform society to function consistently with the requirements to achieve a $1.5^{\circ} \mathrm{C}$ world for each Shared Socio-economic Pathway (SSP) as a result of the combination of different levels of capitals and capacities in each case study in 2100. The capacities assessed are stewarding $(S)$, unlocking $(U)$, transformative $(T)$ and orchestrating $(O)$. Their position on the $y$ axis depends on the combined level of human and social capital. 
Because of the high levels of both capacities and capitals, SSP1 has generally "very high" potential to transform. However, because people are generally more satisfied with this world and there is less impetus for transformative change, this manifests in medium unlocking and "high" (rather than "very high") transformative capacities. In contrast, SSP3 has "very low" or "low" potential in all case studies, as the capitals and capacities are low due to the power of "elites" coupled with conflicts and disparities. However stewarding, unlocking and orchestrating capacity can grow as people organise themselves into communities of interest to counter the status quo, and to share resources such as food (as in the Hungarian and Scottish case studies). This provides some stability and decreases conflict, albeit with larger inequalities than at present. In the Eur-SSP3, the European Union collapses but "richer (ex) Member States" can still afford clean technology, clean water, energy and health services.

SSP4 tends to have "low" or "medium" potential across all case studies. This is because cohesion, collaboration and networks exist within social classes (unlike the more conflictual SSP3 scenarios). Capacities and capitals are high for the elite, who adopt green technology, but low for the majority. This stratification and social exclusion limit the capitals and capacities, and thus the overall potential to transform. Despite generally having higher capitals than SSP3, due to more stability and economic growth, the overall potential of SSP4 is similar to or only slightly higher than SSP3 because the capacities tend to change little over time.

The SSP5 potential, in contrast, ranges from "very low" to "very high". In Europe and Scotland high stewarding and transformative capacity are available, as risk-taking and uncertainty are embraced and innovation is embedded. However, the lack of engaged political culture tends to reduce the potential in all case studies. A U-turn towards sustainability emerges in all SSP 5 case studies by 2100, but this happens smoothly in Europe and Scotland whereas in Hungary and Iberia, with lower transformative potential, the transition is much more chaotic.

In summary, these results show important differences in the way in which capacities are manifested both between case studies and between SSPs. For example, in SSP5 (and to some extent in SSP4) transformative capacities enable large-scale deployment of high-tech solutions, whereas in SSP3 unlocking and orchestrating capacities can grow and enable low-technology community-based action and social innovation.

\section{Discussion}

\subsection{Lessons learned: understanding potential in scenarios}

In the theoretical framework we have assumed that the capacities of actors to mobilise capitals can explain the potential to achieve the $1.5^{\circ} \mathrm{C}$ target. The results have shown that using the combined capitals-capacities framework allowed us to systematically identify the enabling and constraining conditions in the scenarios. This results in further enriching the understanding of the scenarios, with the capitals-capacities framework acting as the bridging framework between scenarios and policy.

The analysis of capitals and capacities within the locally derived European scenarios reinforces the ability of SSP1 to deliver mitigation to meet RCP2.6, and confirms the finding that SSP3 is unlikely to be able to meet RCP2.6 
(Riahi et al. 2017), unless the turbulence in the scenario leads to major institutional and lifestyle changes (Marquart-Pyatt et al. 2014, Longhurst et al. 2016, Schanes et al. 2018). For SSP4 and SSP5, which rely mainly on technological and land-based mitigation, the analysis raises doubts over the ability of society to deliver the level of mitigation required to achieve RCP2.6, given the relatively weak and uneven levels of human and social capital and governance capacity. To meet the $1.5^{\circ} \mathrm{C}$ target, even higher levels of mitigation would be required, which emphasises that only SSP1 might have a good chance of meeting this target.

It is worth noting that the IAM modelling of the global SSP-RCP scenarios reported in Riahi et al. (2017) is intended as a reference case on which further analysis of climate impacts and adaptation can be built, and therefore does not consider the feedback effects of climate change on socio-economic systems (e.g. via impacts on ecosystems, energy systems, infrastructure or health). Given that some level of warming is implicit in all scenarios, even those which eventually achieve a RCP 2.6 or $1.5^{\circ} \mathrm{C}$ target (possibly after overshoot), these potential negative feedbacks are significant. Consideration of the capitals and capacities framework helps to illustrate that climate change could negatively affect all five types of capital, which could further reduce the chances of reaching climate targets. The SSP1 scenario, which acts early and strongly to limit climate change and does not rely on overshoot followed by negative emissions, is likely to minimise these negative climate feedback effects and maximise the chances of successful mitigation. The choice of mitigation action could also create positive or negative feedbacks on capacity, as with the example of high food prices for SSP4 reported in Popp et al. (2017). Again, SSP1 with its focus on reduced demand for resources minimises this type of impact. Similarly, high levels of capital and capacity will foster more effective adaptation to climate impacts, which in turn will reduce the damage from climate change.

The four "mitigation types" used in our framework are derived from macro-scale mitigation studies, such as van Vuuren et al. (2008), Riahi et al. (2017) and Fujimori et al. (2018). In local SSPs, the boundaries between those types become more blurred. In future assessments, the categories need to be explicitly assessed to capture the full potential of SSPs. For example, the results of SSP5 show that, in spite of lower potential for institutional and lifestyle change, there could be potential for actors to move towards the goal in ways that are (1) not covered by the categories or (2) fall between the categories. It is therefore necessary to inform global assessments with results from continental and local case studies (Kok et al. 2017b, Rosa et al. 2017, Obermeister et al. 2018) and increase the relevance of mitigation at multiple levels.

However, there was some conceptual mismatch between the results in Figures 4 and 5 and our framework of capacities (Figure 1). The main mismatch was for the stewarding capacity in SSP1 and SSP5. With low challenges to adaptation and mitigation, SSP1 implies some level of transformation towards the $1.5^{\circ} \mathrm{C}$ target. However the stewarding capacity inferred from analysis of the stakeholder-derived scenario did not fit perfectly in either the "medium" or "high" category in our framework (Table 1). This mismatch results from the normative conceptualisation of the capacities as ideal-type conditions and actor abilities, while the SSPs outline very divergent socio-economic scenarios. We nevertheless show that the application of the framework enriches the for understanding potential in scenarios, by providing overarching analytical categories. 
The mismatches between capacity categories and challenges to mitigation and adaptation assumptions behind the European SSPs can be explained by the uncertainty due to (1) the interpretative nature of the capacity categories and (2) the diverging worldviews and opinions on the social challenges to sustainability and the $1.5^{\circ} \mathrm{C}$ target. Although studies such as Rockström et al. (2017) suggest clear decadal steps to be undertaken at global level for the road to $1.5^{\circ} \mathrm{C}$ target, the sub-global level shows diverging opinions because different beliefs and stakes are accounted for in order to enable the (global) action. This study adds the capitals and capacities dimensions to the SSP-RCP framework to complement actor-based, participatory approaches (Klein and Juhola, 2014), narrativesonly approaches (Nilsson et al., 2017) and fully empirical studies that cannot be directly applicable in other geographical areas or sectors (Chaudhury et al., 2013; Vervoort et al., 2014). Because the approach is systematic, it can be applied and tested in other geographical areas and sectors to increase comparability, in spite of the inevitable interpretative nature of narratives. However, future application could be hampered by the approach being intensive and therefore needing expensive external human and financial resources. Nevertheless, because of its conceptual simplicity and inclusion of actor-based capacity analysis, the approach could appeal to decisionmakers and practitioners (Klein and Juhola, 2014) and enhance the use of scenarios to explore how agency affects the future (Falardeau et al. 2019). The categories of capacities in Table 1 enable impact modellers to include qualitative and quantitative information about the SSP context, beyond GDP and population-based indicators (Barrington-Leigh and Galbraith, 2019).

\subsection{Potential application of the SSP capital and capacity framework to Integrated Assessment Modelling}

The assessment of capitals and capacities for each scenario can complement the use of Integrated Assessment Models (IAMs). Our framework can provide a 'reality check' to indicate whether the societal conditions consistent with each SSP would actually allow the relevant actors to build and mobilise the capitals that are required to implement the mitigation options to meet a given RCP. In this section we link the level of capitals and capacities within each case study SSP (from Figures 4 and 5) to the mitigation and transformation options required to achieve the $1.5^{\circ} \mathrm{C}$ target (Figure 1), and consider the implications for IAM modelling.

For SSP1, all four case studies envisage that the level of social and human capital and the stewarding, transformative and orchestrating capacities increase to high levels by 2100 , with the unlocking capacity starting high but falling to medium by 2100 as most citizens become satisfied with the status quo. The potential to implement all four types of mitigation (technological, institutional, lifestyle and land-use) is therefore generally high, if we assume that the high social and human capital will enable the high levels of manufactured and financial capital that are required for technological mitigation. Natural capital also increases in SSP1 (e.g. a large increase for Iberia and moderate increase for Hungary by 2100), indicating that land-based mitigation would also be viable, especially as there is a high level of stewarding and transformative capacity.

This can be compared with the mitigation actions required to reach RCP2.6 from the SSP1 baseline for the OECD region of Europe according to IAM modelling (Bauer et al., 2017; Bauer et al., 2016; Popp et al., 2017; van Vuuren et al., 2017), bearing in mind that even stronger mitigation (beyond $\mathrm{RCP} 2.6$ ) will be required to reach the $1.5^{\circ} \mathrm{C}$ 
target. Mitigation in the SSP1xRCP2.6 IAM starts with a strong focus on reducing energy demand, through both technological and lifestyle measures. After 2040 there is a major shift from fossil fuel towards biomass and renewable energy, as well as extensive afforestation, which is made possible by the low demand for meat which frees up land for biomass and forests. This scenario thus involves rapid implementation of all four types of mitigation (technological, institutional, lifestyle and land-based), which in turn requires high levels of all four capacities. Our study complements the IAM modelling by giving confidence that the locally derived versions of SSP1 for Europe are broadly consistent with high levels of these capitals and capacities.

For SSP3, in contrast, levels of social and human capital and orchestrating capacity decrease to low levels in all case studies as governance breaks down and anarchy prevails. Levels of the other capacities vary from low to medium across the case studies, with unlocking potential reaching a high level in the Eur-SSP by 2100 because of general dissatisfaction with the prevailing situation. This means that it is not possible to achieve a significant level of climate change mitigation either through technological innovation (e.g. due to low transformative capacity) or land-use change (low stewarding capacity) consistent with the finding in the IAM literature that RCP 2.6 is not achievable with the global SSP3 (Riahi et al., 2017). However, this study shows that SSP3's turbulence may also enable dramatic (and, sometimes, enforced) behavioural and institutional changes with potential for local reconstruction when networks of people reorganise and effectively oppose the status-quo (when unlocking capacity is high). Similar potential has been identified in the POLFREE project, where low internationalisation and economic growth (as assumed in SSP3) have been linked to reduced GHGs emissions, increased circular economies and overall employment (Schanes et al. 2018 and POLFREE, 2016).

For the unequal and divided society portrayed in SSP4, levels of social and human capital are low in the Eur-SSP and Hungary and medium in Scotland and Iberia. Transformative capacity is medium in Scotland and Iberia, indicating some potential for technological development including wind and solar power in Iberia. The other capacities are medium to low, indicating that it will be difficult to implement a comprehensive mitigation strategy that includes lifestyle change and land-based change. For comparison, the IAM modelling of SSP4 (Bauer et al., 2017; Calvin et al., 2017; Popp et al., 2017) requires very high investment in low-carbon energy technologies (nuclear, renewables and bioenergy with CCS) to reach RCP2.6, because the potential for land-based measures is limited by high population growth and high demand for food. This reliance on low-carbon energy supply results in a very expensive mitigation strategy, with carbon prices reaching over US\$2000/t $\mathrm{CO}_{2}$ (compared to just US\$140/t $\mathrm{CO}_{2}$ in SSP1 which focuses on demand reduction and land use). However, the low level of capitals and capacities in the locally derived SSPs raises doubts that this high level of technical investment and innovation could be achieved in practice. In addition, IAM modelling of SSP4 indicates that food prices would increase by a factor of six (Popp et al., 2017) due to pressure on land for bio-energy and afforestation. This would have implications for human and social capital that could further limit the mitigation potential.

The locally derived fossil-fuel based SSP5 scenarios vary markedly between case studies. There could be a high potential for technological and land-based solutions in the Eur-SSP and Scotland to some extent, though in the other case studies and for other mitigation options the mitigation potential is limited by low capacities or capitals. The IAM modelling for SSP5 indicates that very drastic mitigation is needed to reach RCP2.6, to counter the 
strong growth in energy demand and lock-in to fossil fuel technologies up to 2040 (Bauer et al., 2017; Kriegler et al., 2017; Popp et al., 2017). By $2100,65 \%$ of global final energy demand must be delivered as electricity and $7 \%$ as hydrogen, and fossil fuels are almost completely replaced by renewables, biomass with CCS (to provide negative emissions), and nuclear. Biomass demand in 2100 is the highest of all the scenarios, though a high biomass production efficiency is assumed, limiting the global cropland area to slightly less than in SSP4. As for SSP3, the uneven spread of capitals and capacities highlights potential difficulties with reaching this level of mitigation in practice. The Eur-SSP does provide the required high levels of capital and capacity for technological and land-based mitigation, but the local SSPs reveal limitations in capitals (Scotland), capacities (Iberia) or both (Hungary).

\section{Conclusion}

Our study has developed a transferable method for assessing the ability of society to achieve the societal transformation necessary to meet climate targets, which has been tested across a range of spatial scales in European case studies. The assessment of capitals and capacities in the SSPs has the potential to inform a more realistic assessment of the potential uptake and effectiveness of a range of mitigation options needed to achieve $1.5^{\circ} \mathrm{C}$ by taking account of the diverse scenario-specific constraints and enablers. By integrating social science and participatory approaches with climate and socio-economic scenario modelling outputs, this transdisciplinary method can explore important feedbacks on the capacity for transformation that cannot be included in technoeconomic models.

The results at sub-global level have highlighted different potentials to achieve the $1.5^{\circ} \mathrm{C}$ target for the same SSP across different case study areas, not only due to scale effects, but also to the normativity of the SSPs and the different beliefs and stakes of local actors that must be taken into account in order to enable change at global scale. Even in the most archetypical SSP1 and SSP3 scenarios, the capacities to enable change result in multiple possibilities to act which may lead to trade-offs or give unexpected opportunities for transformation and mitigation, such as in SSP3. The case studies consistently show that the SSPs with least challenges to mitigation, SSP1 and SSP4, have very different potentials for transformation, with SSP1 having a high or very high potential whereas SSP4 is restricted to low or medium potential due to high levels of inequality. Likewise the two SSPs with highest challenges to mitigation, SSP3 and SSP5, have different potentials, with SSP5 having the highest potential in those case study versions with higher capitals and lower social inequality.

This study highlights the critical role played by social and human capital, and also by societal capacity to mobilise and create these capitals despite different socio-economic trends, for example by stewarding and human natural resources, orchestrating collaboration in alignment with long-term goals for positive change, unlocking existing unsustainable path-dependencies in behaviours, values, market patterns, institutions etc., and developing social, technological and governance innovations. These capitals and capacities are essential to enable the rapid innovation, behavioural change and international co-ordination needed to achieve the $1.5^{\circ} \mathrm{C}$ goal. Consideration of future changes in capitals and capacities alongside IAM projections could help to inform policy-making and determine the actions and strategies needed to achieve ambitious climate targets. 


\section{References}

Abbott, K.W., Genschel, P., Snidal, D., Zangl, B. (2015) International organizations as orchestrators. Cambridge University Press.

Akimoto, K., Sano, F., Tomoda, T. (2017) GHG emission pathways until 2300 for the $1.5^{\circ} \mathrm{C}$ temperature rise target and the mitigation costs achieving the pathways. Mitigation and Adaptation Strategies for Global Change, doi: 10.1007/s11027-017-9762-z.

Avelino, F., Wittmayer, J.M. (2016) Shifting Power Relations in Sustainability Transitions: A Multi-actor Perspective. Journal of Environmental Policy \& Planning 18, 628-649, doi: 10.1080/1523908X.2015.1112259.

Barrington-Leigh C, Galbraith E (2019) Feasible future global scenarios for human life evaluations Nature Communications 10:161, doi:10.1038/s41467-018-08002-2

Bauer, N., Calvin, K., Emmerling, J., Fricko, O., Fujimori, S., Hilaire, J., Eom, J., Krey, V., Kriegler, E., Mouratiadou, I., Sytze de Boer, H., van den Berg, M., Carrara, S., Daioglou, V., Drouet, L., Edmonds, J.E., Gernaat, D., Havlik, P., Johnson, N., Klein, D., Kyle, P., Marangoni, G., Masui, T., Pietzcker, R.C., Strubegger, M., Wise, M., Riahi, K., van Vuuren, D.P. (2017) Shared Socio-Economic Pathways of the Energy Sector Quantifying the Narratives. Global Environmental Change 42, 316-330, doi: 10.1016/j.gloenvcha.2016.07.006.

Bauer, N., Hilaire, J., Brecha, R.J., Edmonds, J., Jiang, K., Kriegler, E., Rogner, H.-H., Sferra, F. (2016) Assessing global fossil fuel availability in a scenario framework. Energy 111, 580-592, doi: 10.1016/j.energy.2016.05.088.

Börjeson, L., Höjer, M., Dreborg, K.-H., Ekvall, T., Finnveden, G. (2006) Scenario types and techniques: Towards a user's guide. Futures 38, 723-739, doi: 10.1016/j.futures.2005.12.002.

Calvin, K., Bond-Lamberty, B., Clarke, L., Edmonds, J., Eom, J., Hartin, C., Kim, S., Kyle, P., Link, R., Moss, R., McJeon, H., Patel, P., Smith, S., Waldhoff, S., Wise, M. (2017) The SSP4: A world of deepening inequality. Global Environmental Change 42, 284-296, doi: 10.1016/j.gloenvcha.2016.06.010.

Carlsen, H., Dreborg, K.H., Wikman-Svahn, P. (2013) Tailor-made scenario planning for local adaptation to climate change. Mitigation and Adaptation Strategies for Global Change 18, 1239-1255, doi: 10.1007/s11027012-9419-x.

Chan, S., Falkner, R., Van Asselt, H., Goldberg, M. (2015) Strengthening non-state climate action: a progress assessment of commitments launched at the 2014 UN Climate Summit.

Chapin, F.S., Carpenter, S.R., Kofinas, G.P., Folke, C., Abel, N., Clark, W.C., Olsson, P., Smith, D.M.S., Walker, B., Young, O.R. (2010) Ecosystem stewardship: sustainability strategies for a rapidly changing planet. Trends in ecology \& evolution 25, 241-249, doi: 10.1016/j.tree.2009.10.008

Chaudhury, M., Vervoort, J., Kristjanson, P., Ericksen, P., Ainslie, A. (2013) Participatory scenarios as a tool to link science and policy on food security under climate change in East Africa. Regional Environmental Change 13, 389-398, doi: 10.1007/s10113-012-0350-1.

Chelleri, L., Waters, J.J., Olazabal, M., Minucci, G. (2015) Resilience trade-offs: addressing multiple scales and temporal aspects of urban resilience. Environment and Urbanization 27, 181-198, doi: $10.1177 / 0956247814550780$.

Dunford, R., Harrison, P.A., Jäger, J., Rounsevell, M.D.A., Tinch, R. (2015) Exploring climate change vulnerability across sectors and scenarios using indicators of impacts and coping capacity. Climatic Change 128, 339-354, doi: 10.1007/s10584-014-1162-8.

Falardeau M, Raudsepp-Hearne C, Bennett EM (2019) A novel approach for co-producing positive scenarios that explore agency: case study from the Canadian Arctic Sustainability Science 14:205-220, doi:10.1007/s11625-018-0620-z.

Feola, G. (2015) Societal transformation in response to global environmental change: A review of emerging concepts. Ambio 44, 376-390, doi: 10.1007/s13280-014-0582-z.

Folke, C., Hahn, T., Olsson, P., Norberg, J. (2005) Adaptive Governance of Social-Ecological Systems. Annual Review of Environment and Resources 30(1): 441-473, doi: 10.1146/annurev.energy.30.050504.144511. 
Folke, C., Carpenter, S., Walker, B., Scheffer, M., Chapin, T., Rockström, J. (2010) Resilience thinking: integrating resilience, adaptability and transformability. Ecology and Society 15.

Folke, C. (2016) Resilience (Republished). Ecology and Society 21(4):44, doi: 10.5751/ES-09088-210444

Frantzeskaki, N., Loorbach, D., Meadowcroft, J. (2012) Governing societal transitions to sustainability. International Journal of Sustainable Development 15, 19-36.

Frantzeskaki, N., Wittmayer, J., Loorbach, D. (2014) The role of partnerships in 'realising'urban sustainability in Rotterdam's City Ports Area, The Netherlands. Journal of Cleaner Production 65, 406-417, doi: 10.1016/j.jclepro.2013.09.023.

Friedlingstein, P., Andrew, R.M., Rogelj, J., Peters, G.P., Canadell, J.G., Knutti, R., Luderer, G., Raupach, M.R., Schaeffer, M., van Vuuren, D.P., Le Quere, C. (2014) Persistent growth of CO2 emissions and implications for reaching climate targets. 7, 709-715, doi: 10.1038/ngeo2248.

Fujimori, S., Hasegawa, T., Ito, A., Takahashi, K., Masui, T. (2018) Gridded emissions and land-use data for 2005-2100 under diverse socioeconomic and climate mitigation scenarios. Scientific Data 5, 180210, doi: $10.18959 / 20180403.001$.

Garmestani, A.S., Benson M.H. (2013) A framework for resilience-based governance of social-ecological systems. Ecology and Society 18(1): 9, doi: 10.5751/ES-05180-180109.

Geels, F.W. (2014) Regime resistance against low-carbon transitions: Introducing politics and power into the multi-level perspective. Theory, Culture \& Society 31, 21-40, doi: 10.1177/0263276414531627.

Giddens, A. (1979) Central problems in social theory: Action, structure, and contradiction in social analysis. Univ of California Press.

Giddens, A. (1986) The constitution of society: Outline of the theory of structuration. Univ of California Press.

Gillard, R., Gouldson, A., Paavola, J., Van Alstine, J. (2016) Transformational responses to climate change: beyond a systems perspective of social change in mitigation and adaptation. Wiley Interdisciplinary Reviews: Climate Change 7, 251-265, doi: 10.1002/wcc.384.

Gramberger, M., Zellmer, K., Kok, K., Metzger, M. (2015) Stakeholder integrated research (STIR): a new approach tested in climate change adaptation research. Climatic Change 128, 201-214, doi: 10.1007/s10584014-1225-x.

Grin, J., Rotmans, J., Schot, J. (2010) Transitions to sustainable development: new directions in the study of long term transformative change. Routledge, ISBN: 0-203-85659-7.

Harrison, P.A., Holman, I.P., Berry, P.M. (2015) Assessing cross-sectoral climate change impacts, vulnerability and adaptation: an introduction to the CLIMSAVE project. Climatic Change 128, 153-167, doi: 10.1007/s10584-015-1324-3.

Harrison, P.A., Dunford, R.W., Holman, I.P., Cojocaru, G., Madsen, M.S., Chen, P.-Y., Pedde, S., Sandars, D., (2018) Differences between low-end and high-end climate change impacts in Europe across multiple sectors. Regional Environmental Change, 1-15, doi: 10.1007/s10113-018-1352-4.

Hermwille, L. (2016) Climate Change as a Transformation Challenge. A New Climate Policy Paradigm? GAIA-Ecological Perspectives for Science and Society 25, 19-22, doi: 10.14512/gaia.25.1.6.

Hodson, M., Marvin, S. (2010) Can cities shape socio-technical transitions and how would we know if they were? Research policy 39, 477-485, doi: 10.1016/j.respol.2010.01.020.

Holman IP, Harrison PA, Metzger MJ (2016). Cross-sectoral impacts of climate and socio-economic change in Scotland - implications for adaptation policy. Regional Environmental Change 16(1), 97-109, doi: 10.1007/s10113-014-0679-8

Hölscher, K., Frantzeskaki, N., Loorbach, D., (2018a) Steering transformation under climate change: capacities for transformative climate governance and the case of Rotterdam, the Netherlands. Regional Environmental Change, doi: 10.1007/s10113-018-1329-3.

Hölscher, K., Frantzeskaki, N., Loorbach, D, (2018b) Transformative and orchestrating capacities in moving beyond experimentation in climate governance in Rotterdam, the Netherlands, in: Turnheim, B., Kivimaa, P., Berkhout, F. (Ed.), Beyond experiments: Understanding how climate governance innovations become embedded. Cambridge University Press. 
Hulme, M. (2016) $1.5^{\circ} \mathrm{C}$ and climate research after the Paris Agreement. Nature Climate Change 6, 222-224, doi: $10.1038 /$ nclimate2939.

IPCC (2018) Global warming of $1.5^{\circ} \mathrm{C}$ : Summary for Policymakers. Approved at the First Joint Session of Working Groups I, II and III of the IPCC and accepted by the 48th Session of the IPCC, Incheon, Republic of Korea, 6 October 2018.

Jäger, J., Rounsevell, M.D.A., Harrison, P.A., Omann, I., Dunford, R., Kammerlander, M., Pataki, G. (2015) Assessing policy robustness of climate change adaptation measures across sectors and scenarios. Climatic Change 128, 395-407, doi: 10.1007/s10584-014-1240-y.

Kivimaa, P., Hildén, M., Huitema, D., Jordan, A., Newig, J. (2017) Experiments in climate governance-a systematic review of research on energy and built environment transitions. Journal of Cleaner Production, doi: 10.1016/j.jclepro.2017.01.027.

Kivimaa, P., Kern, F. (2016) Creative destruction or mere niche support? Innovation policy mixes for sustainability transitions. Research policy 45, 205-217, doi: 10.1016/j.respol.2015.09.008.

Klein, R.J.T., Juhola, S. (2014) A framework for Nordic actor-oriented climate adaptation research. Environmental Science \& Policy 40, 101-115, doi: 10.1016/j.envsci.2014.01.011.

Kok, K., Pedde, S. (2016) IMPRESSIONS socio-economic scenarios. IMPRESSIONS project

Kok, K., Pedde, S., Gramberger, M., Harrison, P.A., Holman, I.P. (2017a) New European socio-economic scenarios for climate change research: operationalising concepts to extend the shared socio-economic pathways. Regional Environmental Change, 1-12, doi: 10.1007/s10113-018-1400-0.

Kok, M.T., Kok, K., Peterson, G.D., Hill, R., Agard, J., Carpenter, S.R. (2017b) Biodiversity and ecosystem services require IPBES to take novel approach to scenarios. Sustainability Science 12, 177-181, doi: 10.1007/s11625-016-0354-8.

Kriegler, E., Bauer, N., Popp, A., Humpenöder, F., Leimbach, M., Strefler, J., Baumstark, L., Bodirsky, B.L., Hilaire, J., Klein, D., Mouratiadou, I., Weindl, I., Bertram, C., Dietrich, J.-P., Luderer, G., Pehl, M., Pietzcker, R., Piontek, F., Lotze-Campen, H., Biewald, A., Bonsch, M., Giannousakis, A., Kreidenweis, U., Müller, C., Rolinski, S., Schultes, A., Schwanitz, J., Stevanovic, M., Calvin, K., Emmerling, J., Fujimori, S., Edenhofer, O. (2017) Fossil-fueled development (SSP5): An energy and resource intensive scenario for the 21st century. Global Environmental Change 42, 297-315, doi: 10.1016/j.gloenvcha.2016.05.015.

Kriegler, E., Edmonds, J., Hallegatte, S., Ebi, K., Kram, T., Riahi, K., Winkler, H., van Vuuren, D. (2014) A new scenario framework for climate change research: the concept of shared climate policy assumptions. Climatic Change 122, 401-414, doi: 10.1007/s10584-013-0971-5.

Kriegler, E., O’Neill, B.C., Hallegatte, S., Kram, T., Lempert, R.J., Moss, R.H., Wilbanks, T. (2012) The need for and use of socio-economic scenarios for climate change analysis: A new approach based on shared socioeconomic pathways. Global Environmental Change 22, 807-822, doi: 10.1016/j.gloenvcha.2012.05.005.

Lempert, R. (2013) Scenarios that illuminate vulnerabilities and robust responses. Climatic Change 117, 627646, doi: 10.1007/s10584-012-0574-6.

Longhurst $\mathrm{N}$ et al. (2016) Experimenting with alternative economies: four emergent counter-narratives of urban economic development. Current opinion in environmental sustainability 22:69-74, doi: 10.1016/j.cosust.2017.04.006.

Loorbach, D. (2014) To transition! Governance panarchy in the new transformation. Inaugural Address; Erasmus University Rotterdam: Rotterdam, The Netherlands.

Loorbach, D., Frantzeskaki, N., Huffenreuter, R.L. (2015) Transition management: taking stock from governance experimentation. The Journal of Corporate Citizenship, 48-67, doi: 10.9774/GLEAF.4700.2015.ju.00008.

Loorbach D., Frantzeskaki N., Avelino F. (2017) Sustainability Transitions Research: Transforming Science and Practice for Societal Change. Annual Review of Environment and Resources 42:599-626, doi: 10.1146/annurev-environ-102014-021340.

Marquart-Pyatt ST, McCright AM, Dietz T, Dunlap RE (2014) Politics eclipses climate extremes for climate change perceptions. Global Environmental Change 29:246-257, doi: 10.1016/j.gloenvcha.2014.10.004. 
Moss, R.H., Edmonds, J.A., Hibbard, K.A., Manning, M.R., Rose, S.K., van Vuuren, D.P., Carter, T.R., Emori, S., Kainuma, M., Kram, T., Meehl, G.A., Mitchell, J.F.B., Nakicenovic, N., Riahi, K., Smith, S.J., Stouffer, R.J., Thomson, A.M., Weyant, J.P., Wilbanks, T.J. (2010) The next generation of scenarios for climate change research and assessment. 463, 747-756, doi: 10.1038/nature08823.

Nilsson, A.E., Bay-Larsen, I., Carlsen, H., van Oort, B., Bjørkan, M., Jylhä, K., Klyuchnikova, E., Masloboev, V., van der Watt, L.-M. (2017) Towards extended shared socio-economic pathways: A combined participatory bottom-up and top-down methodology with results from the Barents region. Global Environmental Change 45, 124-132, doi: 10.1016/j.gloenvcha.2017.06.001.

O'Brien, K. (2015) Political agency: The key to tackling climate change. Science 350, 1170-1171, doi: $10.1126 /$ science.aad0267.

O'Brien, K.L. (2016) Climate change and social transformations: is it time for a quantum leap? Wiley Interdisciplinary Reviews: Climate Change 7, 618-626, doi: 10.1002/wcc.413.

O'Neill, B.C., Tebaldi, C., Van Vuuren, D.P., Eyring, V., Friedlingstein, P., Hurtt, G., Knutti, R., Kriegler, E., Lamarque, J.-F., Lowe, J. (2016) The scenario model intercomparison project (ScenarioMIP) for CMIP6. Geoscientific Model Development 9, 3461, doi: 10.5194/gmd-9-3461-2016.

O’Neill, B., Kriegler, E., Riahi, K., Ebi, K., Hallegatte, S., Carter, T., Mathur, R., van Vuuren, D. (2015) A new scenario framework for climate change research: the concept of shared socio-economic pathways. Climatic Change 122, 387-400, doi: 10.1007/s10584-013-0905-2.

O’Neill, B.C., Kriegler, E., Ebi, K.L., Kemp-Benedict, E., Riahi, K., Rothman, D.S., van Ruijven, B.J., van Vuuren, D.P., Birkmann, J., Kok, K., Levy, M., Solecki, W. (2017) The roads ahead: Narratives for shared socio-economic pathways describing world futures in the 21st century. Global Environmental Change 42, 169-180, doi: 10.1016/j.gloenvcha.2015.01.004.

Obermeister, N. (2018) Local knowledge, global ambitions: IPBES and the advent of multi-scale models and scenarios. Sustainability Science, doi: 10.1007/s11625-018-0616-8.

Olsson, P., Galaz, V., Boonstra, W. (2014) Sustainability transformations: a resilience perspective. Ecology and Society 19, doi: 10.5751/ES-06799-190401.

Pedde, S., Kok, K., Onigkeit, J., Brown, C., Holman, I., Harrison, P.A. (2018) Bridging uncertainty concepts across narratives and simulations in environmental scenarios. Regional Environmental Change, doi: 10.1007/s10113-018-1338-2.

Pilli-Sihvola, K., van Oort, B., Hanssen-Bauer, I., Ollikainen, M., Rummukainen, M., Tuomenvirta, H. (2015) Communication and use of climate scenarios for climate change adaptation in Finland, Sweden and Norway. Local Environment 20, 510-524, doi: 10.1080/13549839.2014.967757.

Jäger (2016). Civil Society Leads - In Short. POLFREE project website http://polfree.seri.at/civil-societyleads-in-short/ (last accessed 14 October 2018).

Popp, A., Calvin, K., Fujimori, S., Havlik, P., Humpenöder, F., Stehfest, E., Bodirsky, B.L., Dietrich, J.P., Doelmann, J.C., Gusti, M., Hasegawa, T., Kyle, P., Obersteiner, M., Tabeau, A., Takahashi, K., Valin, H., Waldhoff, S., Weindl, I., Wise, M., Kriegler, E., Lotze-Campen, H., Fricko, O., Riahi, K., Vuuren, D.P.v. (2017) Land-use futures in the shared socio-economic pathways. Global Environmental Change 42, 331-345, doi: 10.1016/j.gloenvcha.2016.10.002.

Porritt, J., (2007) The Five Capitals Framework, Capitalism as if the World Matters. Earthscan, London, UK, pp. 137-142, ISBN: 978-1-84407-193-7.

Rauschmayer, F., Bauler, T., Schäpke, N. (2015) Towards a thick understanding of sustainability transitionsLinking transition management, capabilities and social practices. Ecological economics 109, 211-221, doi: 10.1016/j.ecolecon.2014.11.018.

Raven, R., van den Bosch, S., Weterings, R. (2010) Transitions and strategic niche management: towards a competence kit for practitioners. Int. J. Technology Management 51(1):57-74, doi: 10.1504/IJTM.2010.033128.

Riahi, K., van Vuuren, D.P., Kriegler, E., Edmonds, J., O’Neill, B.C., Fujimori, S., Bauer, N., Calvin, K., Dellink, R., Fricko, O., Lutz, W., Popp, A., Cuaresma, J.C., Kc, S., Leimbach, M., Jiang, L., Kram, T., Rao, S., Emmerling, J., Ebi, K., Hasegawa, T., Havlik, P., Humpenöder, F., Da Silva, L.A., Smith, S., Stehfest, E., Bosetti, V., Eom, J., Gernaat, D., Masui, T., Rogelj, J., Strefler, J., Drouet, L., Krey, V., Luderer, G., Harmsen, 
M., Takahashi, K., Baumstark, L., Doelman, J.C., Kainuma, M., Klimont, Z., Marangoni, G., Lotze-Campen, H., Obersteiner, M., Tabeau, A., Tavoni, M. (2017) The Shared Socio-economic Pathways and their energy, land use, and greenhouse gas emissions implications: An overview. Global Environmental Change 42, 153168, doi: 10.1016/j.gloenvcha.2016.05.009.

Rockström, J., Gaffney, O., Rogelj, J., Meinshausen, M., Nakicenovic, N., Schellnhuber, H.J. (2017) A roadmap for rapid decarbonization. Science 355, 1269-1271, doi: 10.1126/science.aah3443.

Rogelj, J., den Elzen, M., Höhne, N., Fransen, T., Fekete, H., Winkler, H., Schaeffer, R., Sha, F., Riahi, K., Meinshausen, M. (2016) Paris Agreement climate proposals need a boost to keep warming well below $2{ }^{\circ} \mathrm{C}$. 534, 631-639, doi: 10.1038/nature18307.

Rogelj, J., Hare, B., Nabel, J., Macey, K., Schaeffer, M., Markmann, K., Meinshausen, M. (2009) Halfway to Copenhagen, no way to $2^{\circ} \mathrm{C}$. Nature Reports Climate Change, 81-83.

Rogelj, J., Luderer, G., Pietzcker, R.C., Kriegler, E., Schaeffer, M., Krey, V., Riahi, K. (2015) Energy system transformations for limiting end-of-century warming to below 1.5 [deg]C. Nature Climate Change 5, 519-527, doi: $10.1038 /$ nclimate2572.

Rosa, I.M.D., Pereira, H.M., Ferrier, S., Alkemade, R., Acosta, L.A., Akcakaya, H.R., den Belder, E., Fazel, A.M., Fujimori, S., Harfoot, M., Harhash, K.A., Harrison, P.A., Hauck, J., Hendriks, R.J.J., Hernández, G., Jetz, W., Karlsson-Vinkhuyzen, S.I., Kim, H., King, N., Kok, M.T.J., Kolomytsev, G.O., Lazarova, T., Leadley, P., Lundquist, C.J., García Márquez, J., Meyer, C., Navarro, L.M., Nesshöver, C., Ngo, H.T., Ninan, K.N., Palomo, M.G., Pereira, L.M., Peterson, G.D., Pichs, R., Popp, A., Purvis, A., Ravera, F., Rondinini, C., Sathyapalan, J., Schipper, A.M., Seppelt, R., Settele, J., Sitas, N., van Vuuren, D. (2017) Multiscale scenarios for nature futures. Nature Ecology \& Evolution 1, 1416-1419, doi: 10.1038/s41559-017-0273-9.

Schanes, K., J. Jäger, and P. Drummond (2018) Three Scenario Narratives for a Resource-Efficient and LowCarbon Europe in 2050. Ecological Economics, 70-79, doi: 10.1016/j.ecolecon.2018.02.009.

Tàbara, J.D., Mangalagiu, D., Kupers, R., Jaeger, C.C., Mandel, A., Paroussos, L. (2013) Transformative targets in sustainability policy making: the case of the $30 \%$ EU mitigation goal. Journal of Environmental Planning and Management 56, 1180-1191, doi: 10.1080/09640568.2012.716365.

Tàbara, J.D., Frantzeskaki, N., Hölscher, K., Pedde, S., Kok, K., Lamperti, F., Christensen, J.H., Jäger, J., Berry, P. (2018a) Positive tipping points in a rapidly warming world. Current Opinion in Environmental Sustainability 31, 120-129, doi: 10.1016/j.cosust.2018.01.012.

Tàbara, J.D., Cots, F., Pedde, S., Hölscher, K., Kok, K., Lovanova, A., Capela Lourenço, T., Frantzeskaki, N., Etherington, J. (2018b) Exploring Institutional Transformations to Address High-End Climate Change in Iberia. Sustainability 10, 161, doi: 10.3390/su10010161.

Tinch, R., Jäger, J., Omann, I., Harrison, P.A., Wesely, J., Dunford, R. (2015) Applying a capitals framework to measuring coping and adaptive capacity in integrated assessment models. Climatic Change 128, 323-337, doi: $10.1007 / \mathrm{s} 10584-014-1299-5$.

van der Zwaan, B., Calvin, K.V., Clarke, L.E. (2016) Climate Mitigation in Latin America: Implications for Energy and Land Use: Preface to the Special Section on the findings of the CLIMACAP-LAMP Project. Energy Economics, Medium: ED; Size: p. 495-498, doi: 10.1016/j.eneco.2016.05.005.

van Ruijven, B., Levy, M., Agrawal, A., Biermann, F., Birkmann, J., Carter, T., Ebi, K., Garschagen, M., Jones, B., Jones, R., Kemp-Benedict, E., Kok, M., Kok, K., Lemos, M., Lucas, P., Orlove, B., Pachauri, S., Parris, T., Patwardhan, A., Petersen, A., Preston, B., Ribot, J., Rothman, D., Schweizer, V. (2014) Enhancing the relevance of Shared Socio-economic Pathways for climate change impacts, adaptation and vulnerability research. Climatic Change 122, 481-494, doi: 10.1007/s10584-013-0931-0 .

Van Vuuren, D.P., Meinshausen, M., Plattner, G.-K., Joos, F., Strassmann, K.M., Smith, S.J., Wigley, T.M.L., Raper, S.C.B., Riahi, K., de la Chesnaye, F., den Elzen, M.G.J., Fujino, J., Jiang, K., Nakicenovic, N., Paltsev, S., Reilly, J.M. (2008) Temperature increase of 21 st century mitigation scenarios. Proceedings of the National Academy of Sciences, doi: 10.1073/pnas.0711129105.

van Vuuren, D. P., Kriegler, E., O’Neill, B., Ebi, K., Riahi, K., Carter, T., Edmonds, J., Hallegatte, S., Kram, T., Mathur, R., Winkler, H. (2014) A new scenario framework for Climate Change Research: scenario matrix architecture. Climatic Change 122, 373-386, doi: 10.1007/s10584-013-0906-1.

van Vuuren, D.P., Stehfest, E., Gernaat, D.E.H.J., Doelman, J.C., van den Berg, M., Harmsen, M., de Boer, H.S., Bouwman, L.F., Daioglou, V., Edelenbosch, O.Y., Girod, B., Kram, T., Lassaletta, L., Lucas, P.L., van 
Meijl, H., Müller, C., van Ruijven, B.J., van der Sluis, S., Tabeau, A. (2017) Energy, land-use and greenhouse gas emissions trajectories under a green growth paradigm. Global Environmental Change 42, 237-250, doi: 10.1016/j.gloenvcha.2016.05.008.

Vervoort, J.M., Thornton, P.K., Kristjanson, P., Förch, W., Ericksen, P.J., Kok, K., Ingram, J.S.I., Herrero, M., Palazzo, A., Helfgott, A.E.S., Wilkinson, A., Havlík, P., Mason-D’Croz, D., Jost, C. (2014) Challenges to scenario-guided adaptive action on food security under climate change. Global Environmental Change 28, 383-394, doi: 10.1016/j.gloenvcha.2014.03.001.

Westley, F., Olsson, P., Folke, C., Homer-Dixon, T., Vredenburg, H., Loorbach, D., Thompson, J., Nilsson, M., Lambin, E., Sendzimir, J. (2011) Tipping toward sustainability: emerging pathways of transformation. AMBIO: A Journal of the Human Environment 40, 762-780, doi: 10.1007/s13280-011-0186-9.

Westley, F., Tjornbo, O., Schultz, L., Olsson, P., Folke, C., Crona, B., Bodin, Ö. (2013) A theory of transformative agency in linked social-ecological systems. Ecology and Society 18, doi: 10.5751/ES-05072180327. 